\title{
Preparation of Polymer-Mineral Nanocomposites Based on Vinyl Monomers and Dispersed Inorganic Oxides
}

\author{
Volodymyr Dutka* ${ }^{\circledR}$, Yaroslav Kovalskyi, Olena Aksimentyeva, Nataliya Oshchapovska \\ Department of Physical and Colloid Chemistry, Ivan Franko National University of Lviv, Lviv, Ukraine \\ Email: ^vdutka@ukr.net, yakovalskyi@gmail.com, aksimen@ukr.net, natalia.matsyuk88@ukr.net
}

How to cite this paper: Dutka, V., Kovalskyi, Y., Aksimentyeva, O. and Oshchapovska, N. (2021) Preparation of Polymer-Mineral Nanocomposites Based on Vinyl Monomers and Dispersed Inorganic Oxides. Advances in Chemical Engineering and Science, 11, 18-28. https://doi.org/10.4236/aces.2021.111002

Received: July 24, 2020

Accepted: December 6, 2020

Published: December 9, 2020

Copyright $\odot 2021$ by author(s) and Scientific Research Publishing Inc. This work is licensed under the Creative Commons Attribution International License (CC BY 4.0). http://creativecommons.org/licenses/by/4.0/

\begin{abstract}
The polymer-mineral composites were synthesized using vinyl monomers styrene, methyl acrylate, and butyl acrylate with nano dispersed oxides $\mathrm{Fe}_{2} \mathrm{O}_{3}$, $\mathrm{Cr}_{2} \mathrm{O}_{3}, \mathrm{~V}_{2} \mathrm{O}_{5}$ and $\mathrm{SiO}_{2}$ in the presence of benzoyl peroxide and other peroxide initiators. Benzoyl peroxide adsorption on $\mathrm{Fe}_{2} \mathrm{O}_{3}, \mathrm{Cr}_{2} \mathrm{O}_{3}$, and $\mathrm{V}_{2} \mathrm{O}_{5}$ surfaces was studied. The adsorption parameters were found: adsorption-desorption equilibrium constants, maximum adsorption, and the area occupied by the molecule benzoyl peroxide on the surface of the adsorbent. The molecular weights of the polymers in the composites and the degree of grafting of the macromolecules of the polymer to the surface of oxides were studied. It has been found that the surface of the dispersed oxides influences the rate of thermal decomposition of the peroxide initiators and the polymerization parameters of the vinyl monomers.
\end{abstract}

\section{Keywords}

Polymer-Mineral Composites, Organic Peroxides, Radical Polymerization, Peroxide Thermal Degradation, Metal Oxides, Adsorption, Effect of Surface

\section{Introduction}

Polymer-mineral composites have unique properties. The filler performs many functions in the composite, providing the material with specific properties [1] [2]. The hybrid organic-mineral composites are produced with the incorporation of inorganic fillers in the structure of polymer [3] [4] [5]. The polymer matrix incorporated with inorganic particles forms the micro/nanocomposites that can be used in different fields of industry [1] [4]. These composites may be used as optical materials for modern optics and optoelectronic devices [5]. 
Conjugated polymers with different inorganic nanoparticles can form the hybrid structure with electrical conductivity and catalytic functions [6].

The composite of polymers with dispersive metal oxides takes a special place among industrial polymer-mineral composites [3] [7]. The filler in a polymeric composite performs a function of the pigment or stabilizer. The effective method to produce polymer composites with inorganic metal oxide dispersion is "in situ" polymerization. With this method, the formation of a polymer matrix is realized during monomer polymerization in the presence of dispersive mineral filler [7]. The highly developed surface of the mineral filler affects the parameters of the polymerization process due to the adsorption of the monomer and the peroxide radical initiator [8]. This surface can change the molecular masses and the molecular weight distribution of the polymer formed under these conditions. Mineral filler affects the rate of thermal decomposition of peroxide compounds used to initiate polymerization [9] [10].

The nanosize and highly developed surface of the mineral filler due to the adsorption of the monomer and the peroxide radical initiator will affect the parameters of the polymerization process and change the molecular weights and molecular weight distribution of the polymer formed under these conditions.

The purpose of our study was to study the adsorption of peroxide initiators on the surface of dispersed oxides and to identify the features of polymerization in such systems.

\section{Materials and Methods}

Adsorption experiments were performed from a styrene solution at $303 \mathrm{~K}$. To a certain amount of adsorbent in the ampoule was added a styrene solution with a certain amount of benzoyl peroxide (PB). The vials were purged with argon and sealed. The vials were placed in a thermostat and rotated continuously throughout the experiment. After a certain period, the ampoules were removed from the thermostat, centrifuged to precipitate the solids of the adsorbent, and determine the content of peroxide remaining in the styrene solution by an iodometric method [9]. The adsorption of other peroxides on the surface of $\mathrm{Fe}_{2} \mathrm{O}_{3}, \mathrm{Cr}_{2} \mathrm{O}_{3}$, and $\mathrm{V}_{2} \mathrm{O}_{5}$ could not be investigated since at this temperature the decomposition of peroxide compounds on the surface of the filler is observed.

The initiators were benzoyl peroxide (PB), oligomeric peroxide of sebacic acid (OPSA), tret-butyl hydroperoxide (HPTB), and diacyl diperoxide of didecanoyl adipinate (DP). Peroxide compounds were synthesized by methods [11] [12] [13]. In the polymerization experiments used PB, DP, and HPTB with the content of the basic substance $98.5 \%-99.5 \%$. The degree of polycondensation of OPSA was 10 - 20. Styrene (ST), methyl acrylate (MA) and butyl acrylate (BA) were used as monomers, which were purified from inhibitors according to the methods [11]. The polymerization rate was studied by the dilatometric method. Before polymerization, the monomer was degassed in vacuum. In all cases, the dilatometer volume was $100 \mathrm{ml}$. During the polymerization, the reaction mixture was effectively stirred with a magnetic stirrer at such a speed that the dispersed 
mineral was evenly distributed over the reaction mixture. The polymerization of the investigated vinyl monomers was carried out before the conversion of $10 \%$ $12 \%$. The error in determining the polymerization rate did not exceed $3 \%$. After polymerization, the polymer composite was precipitated with methanol, dried, and studied its physicochemical properties.

The disperse oxides $\mathrm{Fe}_{2} \mathrm{O}_{3}, \mathrm{Cr}_{2} \mathrm{O}_{3}, \mathrm{~V}_{2} \mathrm{O}_{5}$, and $\mathrm{SiO}_{2}$ (aerosil) were used as the dispersed fillers. The specific surface of the investigated dispersed minerals was 75.0, 80.0, and $65.0 \mathrm{~m}^{2} / \mathrm{g}$, respectively. Aerosil used brands A-175 which had a specific surface area $176 \mathrm{~m}^{2} / \mathrm{g}$. Before polymerization, the mineral fillers were maintained at $400^{\circ} \mathrm{C}$ in a vacuum. The degree of grafting of the polymer to the mineral surface $(g$, \%) was investigated after washing the non-grafted polymer $\left(m_{0}\right)$ on a Soxhlet apparatus. A sample of the composite with the polymer grafted to the surface of the filler $\left(m_{0}\right)$ was heated on a derivatograph Q-1500D, burning the polymer to a constant weight of the filler $\left(m_{1}\right)$. The degree of grafting of the polymer to the mineral surface $(g, \%)$ was calculated by the formula:

$$
g=\left[\left(m_{0}-m_{1}\right) / m_{0}\right] \times 100 \% .
$$

The characteristic viscosity $[\eta]$ of polystyrene was determined at $25^{\circ} \mathrm{C}$ in a solution of benzene. The molecular weight of the polymer $(M)$, which was not bound to the mineral surface, was calculated by the formula [14]:

$$
M=1606 \times[\eta]^{1.3} \times 104.15 \text {. }
$$

\section{Results and Discussion}

The adsorption process of studied peroxides is well described by the known Langmuir equation. The adsorption isotherms of $\mathrm{PB}$ on the investigated dispersed minerals are shown in Figure 1. The data obtained are given in the coordinates $1 / A$ on $1 / C$, which allowed us to determine the maximum adsorption

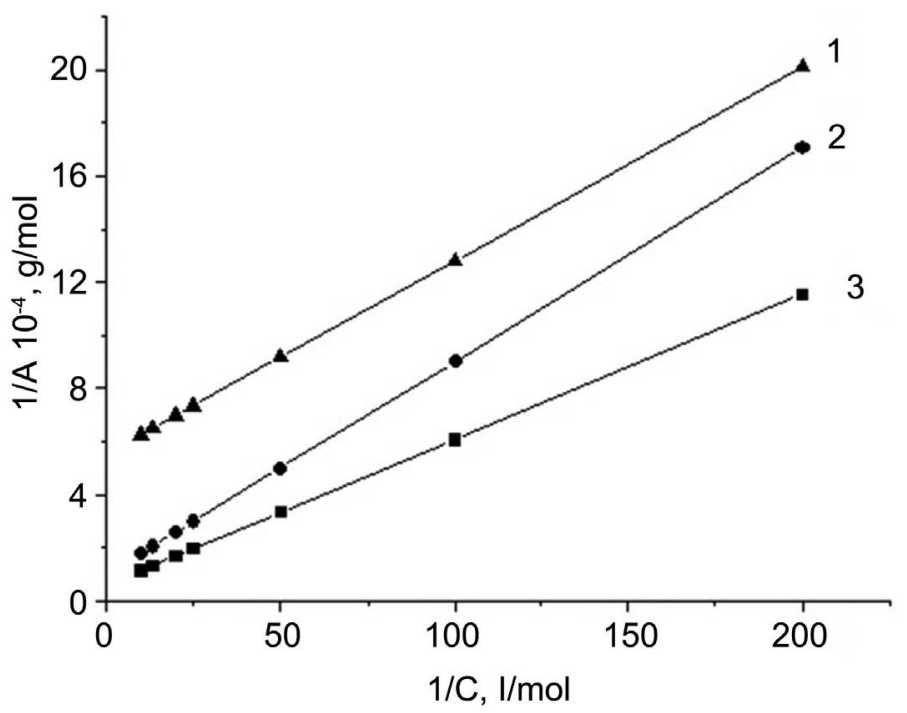

Figure 1. The dependence of $1 / A$ on $1 / C$ for the adsorption process of $\mathrm{PB}$. The solvent is styrene. Adsorbent: 1: $\mathrm{Fe}_{2} \mathrm{O}_{3} ; 2: \mathrm{Cr}_{2} \mathrm{O}_{3} ; 3: \mathrm{V}_{2} \mathrm{O}_{5}$. 
$\left(A_{\infty}\right)$ and the adsorption-desorption equilibrium constant $(K)$. To investigate the adsorption of other initiators was unsuccessful since even at low temperatures there was an intense decomposition of the peroxide compound.

The adsorption-desorption equilibrium for the studied systems was established within 10 - 15 minutes. The parameters of the adsorption process are given in Table 1.

The $\mathrm{PB}$ adsorption increases in the range of $\mathrm{Fe}_{2} \mathrm{O}_{3}>\mathrm{Cr}_{2} \mathrm{O}_{3}>\mathrm{V}_{2} \mathrm{O}_{5}$. The adsorption-desorption equilibrium constants $(K)$ for $\mathrm{Cr}_{2} \mathrm{O}_{3}$ and $\mathrm{V}_{2} \mathrm{O}_{5}$ are almost identical, and for $\mathrm{Fe}_{2} \mathrm{O}_{3}$ this value is 6 times higher. The areas corresponding to the PB molecule in the adsorption layer are 16,10 , and $91 \AA^{2}$. Based on the numerical values of $K$, the values of $\Delta G$ were calculated for the adsorption process. The $\Delta G$ values are close to -6.2 and $-6.0 \mathrm{~kJ} / \mathrm{mol}$ for $\mathrm{Cr}_{2} \mathrm{O}_{3}$ and $\mathrm{V}_{2} \mathrm{O}_{5}$, respectively. For $\mathrm{Fe}_{2} \mathrm{O}_{3}$, the $\Delta G$ value is lower and is $-10.7 \mathrm{~kJ} / \mathrm{mol}$.

Due to the adsorption at the temperatures of 333 - $353 \mathrm{~K}$, the peroxide initiators are decomposed both on the surface of the oxides and in the styrene solution. The free radicals formed by decomposition cause polymerization that flows on the surface of the dispersed mineral and in solution. The polymerization reaction of styrene containing $\mathrm{Fe}_{2} \mathrm{O}_{3}$ flows in solution and on the surface of the filler. The rates of polymerization of styrene at different temperatures in the presence of different peroxide initiators are shown in Table 2.

Table 1. Physical-chemical parameters of benzoyl peroxide adsorption on the surface of $\mathrm{Fe}_{2} \mathrm{O}_{3}, \mathrm{Cr}_{2} \mathrm{O}_{3}$, and $\mathrm{V}_{2} \mathrm{O}_{5}$ from styrene at $303 \mathrm{~K}$.

\begin{tabular}{ccccc}
\hline Adsorbent & $A_{\infty} \cdot 10^{6}, \mathrm{~mol} / \mathrm{g}$ & $S \cdot 10^{20}, \mathrm{~m}^{2}$ & $K, \mathrm{~m}^{3} / \mathrm{kmol}$ & $-\Delta G, \mathrm{~kJ} / \mathrm{mol}$ \\
\hline $\mathrm{Fe}_{2} \mathrm{O}_{3}$ & 1.81 & 91 & 75.63 & 10.7 \\
$\mathrm{Cr}_{2} \mathrm{O}_{3}$ & 10.1 & 16 & 12.32 & 6.2 \\
$\mathrm{~V}_{2} \mathrm{O}_{5}$ & 16.2 & 10 & 11.31 & 6.0 \\
\hline
\end{tabular}

Table 2. The rate of polymerization of styrene in the presence of $\mathrm{Fe}_{2} \mathrm{O}_{3}$ at different temperatures and the activation energy of the polymerization reaction $\left(E_{a}\right)$.

\begin{tabular}{ccccccccc}
\hline \multirow{2}{*}{ Initiator } & $\begin{array}{c}\mathrm{Fe}_{2} \mathrm{O}_{3}, \\
\mathrm{mas} \%\end{array}$ & \multicolumn{7}{c}{ The rate of polymerization $W \cdot 10^{4}, \mathrm{~mol} / \mathrm{L} \cdot \mathrm{s}$} \\
\cline { 3 - 8 } $\mathrm{PB}$ & 0 & 0.69 & 1.14 & 1.75 & 2.67 & 4.42 & - & 86 \\
& 4.0 & 0.92 & 1.38 & 2.08 & 3.02 & 4.48 & 6.42 & 77 \\
& 8.0 & 1.06 & 1.54 & 2.27 & 3.30 & 4.71 & 6.66 & 73 \\
& 9.2 & 1.09 & 1.59 & 2.31 & 3.33 & 4.78 & 6.73 & 72 \\
& 15.3 & 1.19 & 1.72 & 2.45 & 3.50 & 4.86 & 6.80 & 69 \\
& 0 & 0.62 & 1.01 & 1.66 & 2.55 & 4.14 & 6.35 & 92 \\
DP & 4.0 & 0.66 & 1.07 & 1.72 & 2.64 & 4.19 & 6.37 & 90 \\
& 8.0 & 0.68 & 1.10 & 1.78 & 2.70 & 4.25 & 6.44 & 89 \\
& 0 & 1.02 & 1.55 & 2.68 & 4.04 & 6.10 & 9.50 & 89 \\
OPSA & 4.0 & 1.04 & 1.65 & 2.66 & 4.09 & 6.31 & 9.59 & 88 \\
& 8.0 & 1.04 & 1.67 & 2.67 & 4.07 & 6.32 & 9.62 & 88
\end{tabular}

${ }^{*}$ The error in the determination of $E_{a}$ did not exceed $\pm 4.0 \mathrm{~kJ} / \mathrm{mol}$. 
The increase for $\mathrm{Fe}_{2} \mathrm{O}_{3}$ in the polymerization system leads to a decrease in the activation energy of the polymerization reaction $\left(E_{a}\right)$ as shown in Table 3 . This fact indicates the influence of the $\mathrm{Fe}_{2} \mathrm{O}_{3}$ surface on the styrene polymerization. Dispersed $\mathrm{Fe}_{2} \mathrm{O}_{3}$ also affects the rate of thermal decomposition of the peroxide initiator. The rate constants of thermal decomposition $(k)$ of peroxides under the conditions studied are shown in Table 3. When the peroxide disorder on the surface of $\mathrm{Fe}_{2} \mathrm{O}_{3}$ an oxidation-reduction reaction undergoes during which free radicals are produced, that can initiate polymerization. In the case of $\mathrm{PB}$, an increase in $\mathrm{Fe}_{2} \mathrm{O}_{3}$ in the system leads to a significant decrease in the activation energy $\left(E_{a}\right)$ of the thermal decomposition process.

The total rate of the process $(W)$ can be represented as:

$$
W=W_{g}+W_{s},
$$

where $W_{g}$ and $W_{s}$ are the rates of polymerization in solution and on the surface of $\mathrm{Fe}_{2} \mathrm{O}_{3}$, respectively. The rate of polymerization of styrene in a solution can be described by the equation:

$$
W_{g}=K_{1}[I]^{n}[M] .
$$

The polymerization involving the $\mathrm{Fe}_{2} \mathrm{O}_{3}$ surface can be written as:

$$
W_{s}=K_{2} S^{\alpha}[I]^{m}[M]
$$

where are: $K_{1}$ and $K_{2}$ are the total rate constants of the polymerization reaction of styrene at homogeneous and filled systems, respectively; $n$ and $m$ are the initiator reaction order at homogeneous and $\mathrm{Fe}_{2} \mathrm{O}_{3}$-filled systems, respectively; [I] and $[M]$ are the concentrations of the initiator and the monomer; $S$ is the total surface area of the filler; $\alpha$ is the formal-kinetic order of reaction on the surface. Due to the adsorption of the initiator, its concentration in the solution decreases.

\begin{tabular}{|c|c|c|c|c|c|c|c|}
\hline \multirow{2}{*}{ Peroxide } & \multirow{2}{*}{$\begin{array}{l}\mathrm{Fe}_{2} \mathrm{O}_{3} \\
\text { mas } \%\end{array}$} & \multicolumn{5}{|c|}{$k \cdot 10^{5}, \mathrm{~s}^{-1} ; \Delta k= \pm 0.02 k$} & \multirow{2}{*}{${ }^{*} E_{a}, \mathrm{KJ} / \mathrm{mol}$} \\
\hline & & $338 \mathrm{~K}$ & $343 \mathrm{~K}$ & $348 \mathrm{~K}$ & $353 \mathrm{~K}$ & $358 \mathrm{~K}$ & \\
\hline $\mathrm{PB}$ & 0 & - & 1.35 & 2.46 & 5.41 & - & 137 \\
\hline $\mathrm{PB}$ & 4.0 & 0.95 & 1.80 & 3.02 & 5.90 & 9.35 & 116 \\
\hline $\mathrm{PB}$ & 9.2 & 1.40 & 2.31 & 3.56 & 6.52 & 9.42 & 98 \\
\hline $\mathrm{PB}$ & 15.3 & 2.00 & 3.10 & 4.46 & 7.23 & 10.6 & 84 \\
\hline $\mathrm{DP}$ & 0 & 1.20 & 2.28 & 5.25 & 10.5 & 18.2 & 140 \\
\hline $\mathrm{DP}$ & 4.0 & 1.51 & 2.70 & 5.62 & 10.8 & 18.5 & 129 \\
\hline $\mathrm{DP}$ & 8.0 & 1.85 & 3.10 & 6.04 & 10.8 & 18.8 & 118 \\
\hline OPSA & 0 & 3.46 & 6.47 & 11.5 & 21.7 & 38.5 & 119 \\
\hline OPSA & 4.0 & 3.72 & 6.98 & 11.8 & 22.0 & 39.5 & 116 \\
\hline OPSA & 8.0 & 3.91 & 7.23 & 11.9 & 22.4 & 40.0 & 114 \\
\hline
\end{tabular}

Table 3. Kinetic and activation parameters of peroxide thermal decomposition in styrene in $\mathrm{Fe}_{2} \mathrm{O}_{3}$ presence. The concentration of peroxide groups is $0.03 \mathrm{~mol} / \mathrm{L}$.

*The error in the determination of $E_{a}$ did not exceed $\pm 4.0 \mathrm{~kJ} / \mathrm{mol}$. 
The distribution of peroxide between the solution and the $\mathrm{Fe}_{2} \mathrm{O}_{3}$ surface determines the contribution $(\mu)$ to the polymerization rate:

$$
W=(1-\mu) K_{1}[I]^{n}[M]+\mu K_{2} S^{\alpha} I^{m}[M] .
$$

If you divide Equation (4) by (2), you can obtain Equation (5), which will determine the numerical value of $\mu$ :

$$
W / W_{g}=(1-\mu)+\mu K_{2} / K_{1} S^{\alpha}[I]^{m-n} .
$$

As expected, the dependence $W I W_{g}=f(I]^{-n}$ ) is linear (Figure 2), which made it possible to determine the numerical values of $\alpha$ (Table 4). The dependence of $\alpha$ on the surface area of the filler is described by a linear equation:

$$
\alpha=1.54 \times 10^{-2} S-4.1 \times 10^{-2} .
$$

Based on Equation (5), numerical values of $m$ and $\alpha$ can be found. The $\alpha$ values are practically independent of the initiator concentration in the polymerization

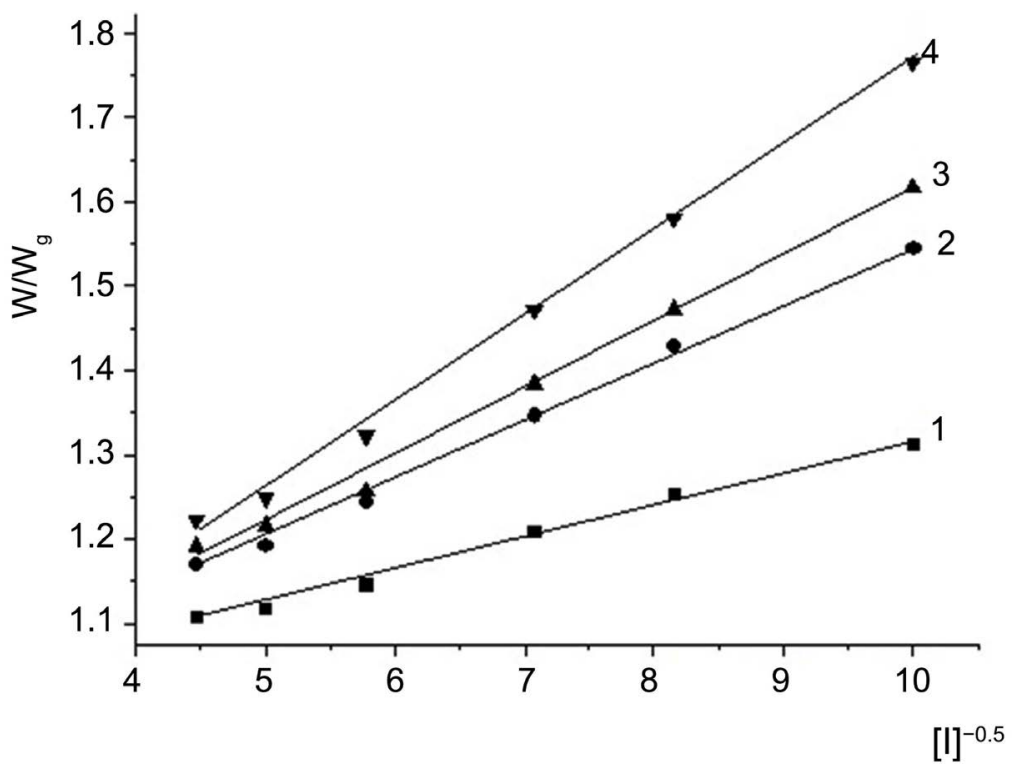

Figure 2. Dependence of $W / W_{g}$ on the concentration of benzoyl peroxide $[I]^{-0.5} . \mathrm{T}=348$ K. The content of $\mathrm{Fe}_{2} \mathrm{O}_{3}$, mas\%: 1: 4.0; 2: 8.0; 3: 9.2; 4: 15.3 .

\begin{tabular}{|c|c|c|c|c|c|c|c|c|c|c|}
\hline \multirow{3}{*}{$\begin{array}{l}\mathrm{Fe}_{2} \mathrm{O}_{3} \\
\text { mas\% }\end{array}$} & \multicolumn{6}{|c|}{$-\alpha$} & \multirow{3}{*}{$-(m-0.5)$} & \multirow{3}{*}{$M$} & \multirow{3}{*}{${ }^{\star} K_{2}$} & \multirow{3}{*}{$L_{n}$} \\
\hline & \multicolumn{6}{|c|}{$[\mathrm{PB}], \mathrm{mol} / \mathrm{L}$} & & & & \\
\hline & 0.010 & 0.015 & 0.020 & 0.030 & 0.040 & 0.050 & & & & \\
\hline 4.0 & & & & & & & 0.50 & 6.0 & 1.54 & 0.18 \\
\hline 8.0 & 0.30 & 0.37 & 0.35 & 0.28 & 0.30 & 0.33 & 0.49 & 13.5 & 1.60 & 0.29 \\
\hline 9.2 & & & & & & & 0.49 & 16.9 & 1.53 & 0.34 \\
\hline 15.3 & & & & & & & 0.50 & 26.0 & 1.54 & 0.43 \\
\hline
\end{tabular}

Table 4. Parameters of the polymerization process initiated by heterogeneous catalytic decomposition of benzoyl peroxide in $\mathrm{Fe}_{2} \mathrm{O}_{3}$ presence at $\mathrm{T}=348 \mathrm{~K}$.

${ }^{*}$ The dimension of the constant $K_{2}$ is $\left(\mathrm{m}^{2} / \mathrm{L}\right)^{-a^{-1}}$. 
system and may be an additional argument in favor of the proposed polymerization model. The fractional value of $\alpha$ indicates the complexity of the processes occurring in the polymerization systems involving the $\mathrm{Fe}_{2} \mathrm{O}_{3}$ surface.

The magnitudes of $m$ at different concentrations of benzoyl peroxide are close to zero due to the same concentration of peroxide per unit surface area of $\mathrm{Fe}_{2} \mathrm{O}_{3}$ under the conditions of our experiments, which is determined by the value of its adsorption. Thus, at $303 \mathrm{~K}$ the adsorption-desorption equilibrium is established very quickly within 5 - 7 minutes, with the maximum adsorption of $\mathrm{PB}$ on $\mathrm{Fe}_{2} \mathrm{O}_{3}$ equal to $16.2 \cdot 10^{-5} \mathrm{~mol} / \mathrm{g}$. It is impossible to determine the numerical value of $A_{\infty}$ at the polymerization temperatures, as a rapid initiator breakdown is observed. But it can be expected that even at higher temperatures the parameter $\mathrm{m}$ will not change and it will be close to zero. Based on the calculated parameters $\mu$, $\alpha$, and $m$, the numerical value of the constant $K_{2}$ was found (Table 4). The obtained values indicate that $K_{2}$ does not depend on the degree of filling and is numerically equal to $1.55 \cdot 10^{-4}\left(\mathrm{~m}^{2} / \mathrm{L}\right)^{-\alpha} \mathrm{S}^{-1}$, which may serve as an additional argument in favor of the proposed polymerization mechanism in the presence of dispersed iron oxide.

Using Equation (4) and the calculated values of $m$ and $\alpha$, we can calculate the fraction of the process initiated due to the heterogeneous catalytic decomposition of peroxide $\left(L_{n}\right)$ in the total polymerization process:

$$
L_{n}=\mu K_{2} S^{-0.32}[M] / W .
$$

The obtained values of $L_{n}$ are shown in Table 4 correspond to the proportion of heterogeneous-catalytic decomposition in the total process for the respective degrees of filling. This fact indicates that all the peroxide, which decomposes on the surface, is involved in the polymerization process. The participation of the $\mathrm{Fe}_{2} \mathrm{O}_{3}$ surface in the polymerization reaction is indicated by the results of the study of the molecular weights of the polymers obtained under the investigated conditions. In the case of initiation of polymerization of PB and DP with increasing mineral content and the system, the molecular weight of polystyrene $(M)$ is reduced by $17 \%-20 \%$. The use of OPSA as an initiator with increasing $\mathrm{Fe}_{2} \mathrm{O}_{3}$ content, molecular weights increase from 40,000 to 72,000 . The degree of grafting of macromolecules of polystyrene $(g)$ to the surface of $\mathrm{Fe}_{2} \mathrm{O}_{3}$ for all investigated cases is almost the same (Table 5 ). It should be noted that the degradation of polystyrene bound to the $\mathrm{Fe}_{2} \mathrm{O}_{3}$ surface begins at temperatures 20 - 30 degrees lower than for mechanical mixtures of the filler polymer. This fact indicates a significant effect of the filler on the thermal-oxidative degradation of polystyrene grafted to the surface of $\mathrm{Fe}_{2} \mathrm{O}_{3}$. Therefore, based on the obtained results, it can be concluded that the surface of iron oxide significantly affects the kinetic parameters of the polymerization reaction, thermal decomposition of peroxide initiators, and the molecular characteristics of polystyrene formed in the presence of a mineral filler.

A study of the effect of chromium oxide on the rate of styrene polymerization reaction indicates that the process rate does not decrease significantly. The study 
Table 5. Kinetic and activation parameters of PB and OPSA thermal decomposition and the efficiency of styrene polymerization initiation $(f)$ in $\mathrm{Cr}_{2} \mathrm{O}_{3}$ presence.

\begin{tabular}{|c|c|c|c|c|c|c|c|c|}
\hline \multirow{2}{*}{$\begin{array}{c}\text { Content of } \mathrm{Cr}_{2} \mathrm{O}_{3}, \\
\text { mas } \%\end{array}$} & \multicolumn{6}{|c|}{$k \cdot 10^{5}, \mathrm{~s}^{-1} ; \Delta k= \pm 0.03 k$} & \multirow{2}{*}{$E_{a}, \mathrm{~kJ} / \mathrm{mol}$} & \multirow{2}{*}{$f$} \\
\hline & $338 \mathrm{~K}$ & $343 \mathrm{~K}$ & $348 \mathrm{~K}$ & $353 \mathrm{~K}$ & $358 \mathrm{~K}$ & $363 \mathrm{~K}$ & & \\
\hline \multicolumn{9}{|c|}{$\mathrm{PB}, 0.03 \mathrm{~mol} / \mathrm{L}$} \\
\hline 0 & - & 1.35 & 2.46 & 5.41 & - & 18.6 & 137 & 0.90 \\
\hline 1.0 & 0.77 & 1.55 & 3.05 & 5.83 & 10.7 & 20.0 & 132 & 0.57 \\
\hline 2.0 & 0.84 & 1.71 & 3.33 & 6.11 & 12.4 & - & 134 & 0.51 \\
\hline 3.0 & 0.95 & 2.04 & 3.81 & 6.73 & 13.9 & - & 132 & 0.43 \\
\hline \multicolumn{9}{|c|}{ OPSA, $0.03 \mathrm{~mol} / \mathrm{L}$} \\
\hline 0 & 3.46 & 6.47 & 11.5 & 21.7 & 38.5 & - & 119 & 0.40 \\
\hline 2.0 & 3.77 & 6.84 & 11.8 & 22.3 & 38.6 & - & 117 & 0.35 \\
\hline
\end{tabular}

of the rate of thermal decomposition of peroxides in the presence of $\mathrm{Cr}_{2} \mathrm{O}_{3}$ is given in Table 5.

As in the case of $\mathrm{Fe}_{2} \mathrm{O}_{3}$, an increase in $\mathrm{Cr}_{2} \mathrm{O}_{3}$ leads to a decrease in the value of $E_{\text {a }}$ from $137 \mathrm{~kJ} / \mathrm{mol}$ to $132 \mathrm{~kJ} / \mathrm{mol}$ (Table 5). This indicates the influence of the nature of the surface on the thermal decomposition process. The calculation of the efficiency of initiation of the polymerization process $(f)$ indicates that the peroxide adsorbed on the $\mathrm{Cr}_{2} \mathrm{O}_{3}$ surface is decomposed by a heterolytic mechanism. The heterolysis of the peroxide group does not lead to the formation of free radicals, so the rates of polymerization and thermal degradation, if any, obey the stated patterns.

The study of the molecular masses of polystyrene and the degree of grafting of macromolecules to the mineral's surface of $\mathrm{Fe}_{2} \mathrm{O}_{3}$ and $\mathrm{Cr}_{2} \mathrm{O}_{3}$ at $\mathrm{T}=348 \mathrm{~K}$ are given in Table 6.

During the polymerization of styrene in the presence of $\mathrm{Fe}_{2} \mathrm{O}_{3}$ and $\mathrm{Cr}_{2} \mathrm{O}_{3}$ polymer-mineral composites are formed. The molecular weights of polystyrene and the degree of grafting of macromolecules to the surface of the minerals are influenced by the nature of the initiator and the conditions of the polymerization. Moreover, the increase in the mineral in the polymerization system leads to a decrease in the molecular weight of polystyrene. This fact indicates that the surface of $\mathrm{Fe}_{2} \mathrm{O}_{3}$ and $\mathrm{Cr}_{2} \mathrm{O}_{3}$ is involved in the process of breaking the growing polymer radicals. The degree of grafting of polystyrene macromolecules to the $\mathrm{Fe}_{2} \mathrm{O}_{3}$ surface is approximately the same $3.8 \%-4.6 \%$ (Table 6). The degree of grafting of polystyrene to the $\mathrm{Cr}_{2} \mathrm{O}_{3}$ surface depends on the nature of the peroxide used to initiate the polymerization and for diacyl peroxides (PB and OPSA) they are $0.97 \%-1.2 \%$. For HPTB, the value of $g$ is much higher and equal to $5.8 \%-6.1 \%$. It should be noted that the thermo-oxidative degradation of the investigated composites begins at much lower temperatures than for pure polystyrene.

For polymerization processes in the presence of $\mathrm{V}_{2} \mathrm{O}_{5}$, increasing the content 
Table 6. Molecular masses of polystyrene and the degree of grafting of macromolecules to the surface of $\mathrm{Fe}_{2} \mathrm{O}_{3}$ and $\mathrm{Cr}_{2} \mathrm{O}_{3}$.

\begin{tabular}{|c|c|c|c|c|c|}
\hline $\begin{array}{c}\text { Content of } \\
\mathrm{Fe}_{2} \mathrm{O}_{3} \text {, mas\% }\end{array}$ & $\begin{array}{c}\text { Molecular } \\
\text { masses, } \mathrm{M} \cdot 10^{-3}\end{array}$ & $\begin{array}{l}\text { Degree of } \\
\text { grafting, g\% }\end{array}$ & $\begin{array}{l}\text { Content of } \\
\mathrm{Cr}_{2} \mathrm{O}_{3}, \%\end{array}$ & $\begin{array}{c}\text { Molecular } \\
\text { masses, } \mathrm{M} \cdot 10^{-3}\end{array}$ & $\begin{array}{c}\text { Degree of } \\
\text { grafting, } g \%\end{array}$ \\
\hline \multicolumn{3}{|c|}{$\mathrm{PB}, 0.03 \mathrm{~mol} / \mathrm{L}$} & \multicolumn{3}{|c|}{$\mathrm{PB}, 0.03 \mathrm{~mol} / \mathrm{L}$} \\
\hline 0 & 50 & - & 0 & 50 & - \\
\hline 4.0 & 43 & 4.6 & 1.0 & 50 & 0.98 \\
\hline 8.0 & 39 & 4.5 & 2.0 & 49 & 1.1 \\
\hline 12.2 & 36 & 4.1 & 3.0 & 48 & 1.0 \\
\hline \multicolumn{3}{|c|}{$\mathrm{DP}, 0.03 \mathrm{~mol} / \mathrm{L}$} & \multicolumn{3}{|c|}{ OPSA, $0.03 \mathrm{~mol} / \mathrm{L}$} \\
\hline 0 & 68 & - & 0 & 40 & - \\
\hline 4.0 & 65 & 3.8 & 1.0 & 42 & 0.97 \\
\hline 8.0 & 59 & 3.9 & 3.0 & 45 & 1.2 \\
\hline \multirow[t]{2}{*}{12.2} & 56 & 4.2 & \multicolumn{3}{|c|}{ НРТВ, $0.03 \mathrm{~mol} / \mathrm{L}$} \\
\hline & OPSA, $0.03 \mathrm{~mol} / \mathrm{L}$ & & 0 & 135 & - \\
\hline 0 & 0.5 & 89 & 5.8 & 89 & 5.8 \\
\hline 4.0 & 1.0 & 84 & 6.1 & 84 & 6.1 \\
\hline 8.0 & 2.0 & 80 & 5.9 & 80 & 5.9 \\
\hline 12.2 & 3.0 & 76 & 6.0 & 76 & 6.0 \\
\hline
\end{tabular}

of the filler leads to an increase in the rate of polymerization and a significant decrease in the activation energy of the polymerization (Table 7).

The results obtained indicate the redox nature of the styrene polymerization reaction in the presence of $\mathrm{V}_{2} \mathrm{O}_{5}$. The activation energy of the polymerization process decreases from 86 to $38 \mathrm{~kJ} / \mathrm{mol}$ as the filler content increases. As with the $\mathrm{Fe}_{2} \mathrm{O}_{3}$ and $\mathrm{Cr}_{2} \mathrm{O}_{3}$ composites, the thermal stability of the obtained composites is low.

When aerosil used as filler in the polymerization of methyl acrylate and butyl acrylate, the filler has different effects on the rate of the polymerization (Table 8). It should be noted that the studied system has competitive adsorption of monomers and initiators on the surface of the aerosil.

When changing the amount of aerosil in the polymerization system in the presence of $\mathrm{PB}$, the rate of polymerization of $\mathrm{MA}$ and $\mathrm{BA}$ is practically unchanged, indicating small adsorption of this initiator on the filler. The rate of polymerization increases when OPSA used as an initiator with increasing aerosil content: MA for $52.5 \%$ and BA for $20 \%$.

\section{Conclusion}

Features of the polymerization process are influenced by many factors, such as the nature of the filler surface, the type of peroxide initiator, the nature of the monomer, and the conditions of the process. During polymerization, the surface is involved in the initiation and breakdown reactions of the polymer chains. Part 
Table 7. The rate of polymerization of styrene with different content of $\mathrm{V}_{2} \mathrm{O}_{5}$ in the polymerization system with initiator PB.

\begin{tabular}{ccccccccc}
\hline \multirow{2}{*}{$\begin{array}{c}\text { Content } \\
\mathrm{V}_{2} \mathrm{O}_{5} \text {, mas\% }\end{array}$} & \multicolumn{9}{c}{ Temperature, K } & \begin{tabular}{c}
$E_{a}$ \\
\cline { 3 - 7 }
\end{tabular} & 323 & 328 & 333 & 338 & 343 & 348 & 353 & $\mathrm{~kJ} / \mathrm{mol}$ \\
\hline 0 & - & - & 0.69 & 1.14 & 1.74 & 2.67 & 4.24 & 86 \\
3.0 & 1.05 & 1.75 & 2.79 & 3.35 & 4.51 & 6.32 & - & 64 \\
10.2 & 5.00 & 7.13 & 8.44 & 10.6 & 13.7 & 16.6 & - & 44 \\
21.2 & 11.0 & 13.7 & 17.0 & 21.3 & 23.5 & 32.0 & - & 38 \\
\hline
\end{tabular}

Table 8. Effect of aerosil on the polymerization rate of MA and BA. T $=338 \mathrm{~K}$. The concentration of peroxide groups is $0.001 \mathrm{~mol} / \mathrm{L}$.

\begin{tabular}{ccccccc}
\hline & & \multicolumn{5}{c}{$W \cdot 10^{4}, \mathrm{~mol} / \mathrm{L} ; \Delta W= \pm 0.03 W$} \\
\cline { 3 - 6 } Monomer & Initiator & \multicolumn{5}{c}{ Content of aerosil, mas\% } \\
\cline { 3 - 7 } & & 0 & 1.0 & 2.0 & 3.0 & 4.0 \\
\cline { 3 - 7 } & OPSA & 15.8 & 17.9 & 19.7 & 22.0 & 24.1 \\
MA & PB & 10.3 & 10.3 & 10.3 & 10.3 & 10.3 \\
BA & OPSA & 10.3 & 10.7 & 11.1 & 11.64 & 12.3 \\
BA & PB & 7.84 & 7.84 & 7.85 & 7.84 & 7.84 \\
\hline
\end{tabular}

of the polymer chains is grafted onto the surface of the mineral filler. The filler affects the molecular weights and the degree of grafting of the macromolecules to the surface of the oxide fillers.

\section{Author Contributions}

Conceptualization, V.D. and O.A.; methodology, V.D.; software, Y.K.; validation, N.O., and Y.K.; formal analysis, N.O.; investigation, Y.K.; resources, N.O.; data curation, N.O.; writing original draft preparation, V.D.; writing review and editing, O.A.; visualization, Y.K.; supervision, O.A.; project administration, V.D.; funding acquisition, O.A.

\section{Funding}

This research received no external funding.

\section{Conflicts of Interest}

The authors declare no conflict of interest.

\section{References}

[1] Voronov, S.A. and Varvarenko, S.M. (2011) Peroxide-Containing Macromolecules at the Interface of the Phases. Lviv Polytech, Lviv, Ukraine. (In Ukrainian)

[2] Berlin, A. (2011) Polymer Composite Materials: Structure, Properties, Technology. Profession, St. Petersburg, Russia. (In Russian)

[3] Volkov, C.V., Kovalchuk, E.P., Ogenko, D.M. and Reshetnyak, O.V. (2008) Nano- 
chemistry. Nanosystems. Nanomaterials. Nauk. Dumka, Kiev, Ukraine. (In Ukrainian)

[4] Bruk, M.A. and Pavlov, C.A. (1990) Polymerization on the Surface of Solid. Khimia, Moscow, Russia. (In Russian)

[5] Nedilko, S.G. (2018) Polymer-Oxide Composites: Toward New Optical Materials. Acta Physica Polonica A, 133, 829-837. https://doi.org/10.12693/APhysPolA.133.829

[6] Kumar, V., Kalia, S. and Swart, H.C. (2017) Conducting Polymer Hybrids. In: Springer Series on Polymer and Composite Materials, Springer International Publishing, Cham, Switzerland.

[7] Miller, J.D. and Drelich, J. (1995) Critical Review of Wetting and Adhesion Phenomena in the Preparation of Polymer-Mineral Composites. Mining, Metallurgy \& Exploration 12, 197-204. https://doi.org/10.1007/BF03403103

[8] Dutka, V.S., Kovalskyi, Ya.P. and Dutka, Yu.V. (2013) Adsorption and Decomposition of Diacyl Peroxides on the Surface of Dispersed Oxides. Colloid Journal, 75, 649-655. https://doi.org/10.1134/S1061933X13060057

[9] Dutka, V.S., Kovalskyi, Ya.P. and Dutka, Yu.V. (2016) Polymerization of Vinyl Monomers in Presence of Modified Aerosils. Ukrainian Chemistry Journal, 82, 122-127. (In Ukrainian)

[10] Dutka, V., Kovalskyi, Y. and Dutka, Y. (2014) Features of Styrene Polymerization in the Presence of the Disperse Chromium Oxide. Polymer Journal, 36, 207-212. (In Ukrainian)

[11] Antonovskii, V. and Buzulanova, M. (1978) Analytical Chemistry of Organic Peroxides. Khimia, Moscow, Russia. (In Russian)

[12] Antonovskii, V.I. (1972) Organic Peroxide Initiators. Khimia, Moscow, Russia. (In Russian)

[13] Rahimov, A.I. (1979) Chemistry and Technology of Organic Peroxide Compounds. Khimia, Moscow, Russia. (In Russian)

[14] Ostapovich, B.B., Hertsik, O.M. and Kovalyshyn, Ya.S. (2019) Laboratory Workshop on Chemistry and Technology of High Molecular Weight Compounds. Lviv University, Lviv, Ukraine. (In Ukrainian) 